\title{
Predictors of Post-Discharge 30-Day Hospital Readmission in Decompensated Heart Failure Patients
}

\author{
Camila Sarteschi, ${ }^{\circledR}$ Wayner Viera de Souza, ${ }^{\circledR}{ }^{\circledR}$ Carolina Medeiros, ${ }^{1}{ }^{\circledR}$ Paulo Sergio Rodrigues Oliveira, ${ }^{1}$ Silvia \\ Marinho Martins, ${ }^{3 \oplus}$ Eduarda Ângela Pessoa Cesse ${ }^{2(0}$ \\ Real Hospital Português de Beneficência em Pernambuco - REALCOR, Recife, PE - Brazil \\ Centro de Pesquisas Aggeu Magalhães - FIOCRUZ, Recife, PE - Brazil \\ Pronto Socorro Cardiológico de Pernambuco Professor Luiz Tavares - PROCAPE, Recife, PE - Brazil
}

\section{Abstract}

Background: Heart failure (HF) is worldwide known as a public health issue with high morbimortality. One of the issues related to the evolution of HF is the high rate of hospital readmission caused by decompensation of the clinical condition, with high costs and worsening of ventricular function.

Objective: To quantify the readmission rate and identify the predictors of rehospitalization in patients with acute decompensated heart failure.

Methods: Hospital-based historic cohort of patients admitted with acute decompensated HF in a private hospital from Recife/PE, from January 2008 to February 2016, followed-up for at least 30 days after discharge. Demographic and clinical data of admission, hospitalization, and clinical and late outcomes were analyzed. Logistic regression was used as a strategy to identify the predictors of independent risks.

Results: 312 followed-up patients, average age $73( \pm 14), 61 \%$ males, 51\% NYHA Class III, and 58\% ischemic etiology. Thirty-day readmission rate was $23 \%$. Multivariate analysis identified the independent predictors ejection fraction $<40 \%(\mathrm{OR}=2.1 ; \mathrm{p}=0.009)$, hyponatremia $(\mathrm{OR}=2.9 ; \mathrm{p}=0.022)$ and acute coronary syndrome (ACS) as the cause of decompensation $(\mathrm{OR}=1.1 ; \mathrm{p}=0,026)$. The final model using those three variables presented reasonable discriminatory power (C-Statistics $=0.655-$ HF 95\%: $0.582-0.728$ ) and good calibration (Hosmer-Lemeshow p $=0.925)$.

Conclusions: Among hospitalized patients with acute decompensated heart failure, the rate of readmission was high. Hyponatremia, reduced ejection fraction and ACS as causes of decompensation were robust markers for the prediction of hospital readmission within 30 days of discharge. (Int J Cardiovasc Sci. 2020; 33(2):175-184)

Keywords: Heart Failure; Hospitalization; Patient Readmission; Patient Discharge/trends.

\section{Introduction}

Heart failure (HF) is a chronic disease associated with high morbidity and mortality and is known worldwide as a public health issue due to its significantly increased incidence, especially amongst the elderly population. It is estimated that the prevalence of $\mathrm{HF}$ varies from $1 \%$ of people under 50 to $10 \%$ of people over 80 years of age. ${ }^{1}$

According to North American data, HF affects around 5.5 million patients. Annually, it presents an incidence of 660,000 new cases, with 800,000 to 3.6 million hospitalizations, 300,000 deaths per year and related costs of around 35 billion dollars, being the fifth most frequent cause of hospitalization and the most common amongst the elderly. ${ }^{2}$

In Brazil, according to data from the National Health System - DATASUS (2017), in 2016, there were around 214,000 hospitalizations due to HF, which is $19 \%$ of the hospitalizations for cardiovascular diseases, with in-hospital mortality of $11 \%$ and costs related to

Mailing Address: Camila Sarteschi

REALCOR - Núcleo de Cardiologia do Real Hospital Português - Av. Agamenon Magalhães, 4760. Postal Code: 52010-900, Derby, Recife, PE - Brazil. E-mail: csarteschi@hotmail.com 
hospitalization alone of around BRL 334 million. In same year, in the Northeast of Brazil, hospitalizations for HF were around 48,000, including more than 8,000 in the state of Pernambuco, with $13.7 \%$ mortality. ${ }^{3}$ In First Brazilian Registry of Heart Failure - BREATHE - in-hospital mortality was $12.6 \%$ of 1,263 patients distributed in 51 urban centers in Brazil. ${ }^{4}$

One of the greatest problems related to the outcome of HF refers to high rates of hospital admissions caused by clinical decompensation, generating intense stress to patients and relatives, with high economic cost and great impact on the health system, in addition to worsening of ventricular function. ${ }^{5}$ Studies have demonstrated that each event of clinical decompensation results in additional worsening of ventricular remodeling in $\mathrm{HF}$, resulting in worse heart function and clinical manifestations of heart failure. ${ }^{6}$

The objective of this study is to calculate hospital readmission rate within 30 days of discharge, as well as to identify the main predictors of re-hospitalization of patients with acute decompensated heart failure (ADHF), in order to assist the development of public health policies, with positive impact on the reduction of morbimortality among those patients.

\section{Methods}

Retrospective study with historic cohort of patients assisted at a private hospital from Recife/PE (Brazil), who were in hospital for over 24 hours, from January 2008 to February 2016.

Admitted patients had primary diagnosis of decompensated heart failure, were 18 years of age or older, Functional Class III and IV according to the Classification of the New York Heart Association NYHA. Decompensated heart failure was diagnosed according to the Framingham Study. ${ }^{7}$ Patients with incomplete or unavailable data on their electronic charts, patients submitted to transplantation and minors of 18 years of age were excluded.

Data collection included hospital admission information from the date of admission to medical discharge or inhospital death, and hospital readmission within 30 days of discharge. Information was obtained from medical records, then complemented, when necessary, by consultation with the medical assistant. Data collection instrument was a structured questionnaire, including demographic and clinical variables, complementary tests and the therapy used, besides information about clinical outcomes and post-discharge outcome.

The outcome of interest was hospital readmission within 30 days of discharge. Only hospital readmissions due to cardiac causes were considered in this study. HF etiologies were defined as: a) ischemic heart disease due to previous heart attack, chest angina, previous coronary artery bypass grafting surgery or percutaneous angioplasty, or coronary angiography showing major artery obstructions (> 70\%) in epicardial branches; b) hypertension heart disease, defined as long-term history of systemic hypertension without adequate blood pressure control or long-term use of anti-hypertensive medication associated with the presence of left ventricular hypertrophy on electrocardiogram or echocardiogram; c) valvular heart disease defined as history of previous valvular disease or based on echocardiogram results; d) idiopathic cardiomyopathy in the presence of dilatation and ventricular dysfunction, in the absence of any other evident cause.

Left ventricular ejection fraction (LVEF) was measured by echocardiogram, using the Teichholz formula for records on mode $\mathrm{M}$ or modified Simpson's rule for final left ventricular systolic and diastolic diameter measurements on apical four-chamber view, according to the regulations applicable. All tests were conducted at the echocardiography section of the hospital. ${ }^{8}$

The variable hospital-acquired complication was made by the composition of in-hospital events (dialysis procedure, ventricular arrhythmia, infection, pulmonary embolism and cardiogenic shock), that is to say, if the patient had at least one of the described events, it was considered hospital-acquired complication.

Some of the continuous variables were changed to categorical variables for analytical purposes: ${ }^{9}$ age $(<65$ and $\geq 65$ years), systolic blood pressure $(<115 \mathrm{mmHg}$ and $\geq 115 \mathrm{mmHg})$, heart rate $(\leq 80 \mathrm{bpm}$ and $>80 \mathrm{bpm})$, hospitalization period ( $\leq 7$ days and $>7$ days), creatinine (abnormal: $>1.3 \mathrm{mg} / \mathrm{dl}$ men and $>1.1 \mathrm{mg} / \mathrm{dl}$ women), plasma sodium (altered - hyponatremia: <130 mEq/L), blood urea nitrogen (abnormal: $\geq 92 \mathrm{mg} / \mathrm{dL}$ ) and LVEF $(<40 \%$ and $\geq 40 \%)$. Presence of anemia was based on the World Health Organization (hemoglobin $<13$ g/dl men and hemoglobin < $12 \mathrm{~g} / \mathrm{dl}$ women).

\section{Statistical analysis}

Demographic and clinical characteristics of patients were analyzed using descriptive statistics: mean and 
standard deviation (SD) for quantitative variables and absolute and relative frequencies for qualitative variables. Bivariate analysis, by Pearson's Chi-Square test, was conducted as a strategy to evaluate the correlation between outcome (readmission within 30 days) and the independent variables studied. In order to build a multivariable logistic regression model, we considered all the variables which, in the bivariate analysis, presented an association with readmission with $p<0.20$. The stepwise forward method was applied to select the final model. The selected variables had their interactions, if any, examined by correlation matrix, interactions with correlation coefficient greater or equal to 0.5 were included in the model. Once the final model was defined, model calibration was evaluated by the HosmerLemeshow Goodness-of-fit test. Discrimination capability of the final model was studied by the C-statistic, that is, the area under the curve built from the receiver operating characteristic curve. The program SPSS for Windows, version 21.0 - Statistical Package for Social Sciences (IBM, Armonk, NY) was used to do the statistics calculations. The level of significance assumed was $5 \%$.

The project was approved by the Research Ethics Committee of Centro de Pesquisas Aggeu Magalhães
(CPqAM) of Fiocruz/PE, with CAAE registration number 67404216.8.0000.5190, in accordance with the Declaration of Helsinki.

\section{Results}

This study included 372 patients that met the criteria of inclusion and exclusion from 2008 to 2016. The analyzed sample of 312 patients was created according to Figure 1. Of those patients, $71(22 \%)$ were readmitted within 30 days after hospital discharge. The age of the patients varied from 26 to 99 years of age, with mean 73 $(\mathrm{SD}=14)$ years, with $232(74 \%)$ patients aged 65 or older, the majority of men (62\%), NYHA-Class III (50\%), ischemic etiology (58\%), LVEF $\geq 40 \%$ (57\%) and hospital admission period over 1 week (64\%).

Among previous comorbidities, systemic arterial hypertension (SAH) was present in $86 \%$ of the patients, diabetes mellitus (DM) in $49 \%$, severe kidney disease in $30 \%$ and chronic obstructive pulmonary disease (COPD)/asthma in $18 \%$. The main cause of decompensation was acute coronary syndrome (ACS) (46\%), followed by arrhythmia (25\%) and infection (23\%). Regarding drug therapy during hospitalization,

Patients hospitalized with acute decompensated heart failure from 2008 to 2016

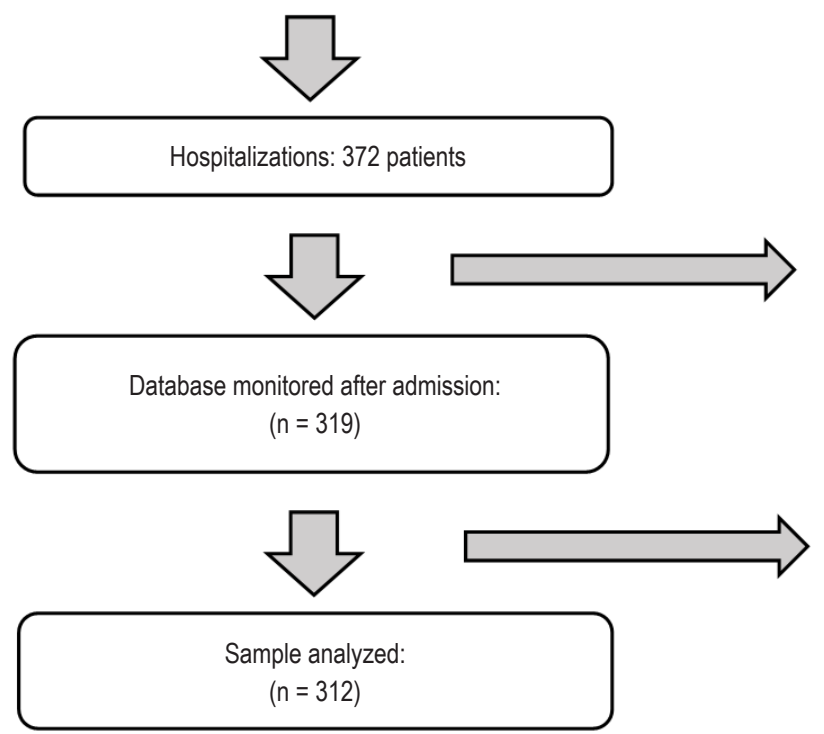

Excluded: 53 patients (death during hospitalization)
Excluded: 7 patients

(loss of follow-up) 
the use of betablockers was seen in $77 \%$ of the patients, as well as angiotensin-converting enzyme inhibitors (ACEI) and angiotensin receptor blockers (ARB). By analyzing only the patients with $\mathrm{HF}$, with reduced ejection fraction $(\mathrm{LVEF}<40 \%)$, that percentage increases to $82 \%$ regarding $\mathrm{ACEI} / \mathrm{ARB}$ and $84 \%$ regarding betablockers. High levels of creatinine were found in $41 \%$ of the patients. Anemia was found in more than half of the analyzed sample (53\%), as $15 \%$ of the patients had abnormal urea levels, and only $8 \%$ had abnormal sodium levels (hyponatremia) on admission (Table 1).
According to the bivariate analysis, the variables with significant correlation with hospital readmission were: ACS as a cause of decompensation ( $p=0.032)$, LVEF ( $p=0.004$ ) and hyponatremia on admission $(p=0.022)$. Previous comorbidities, such as HAS, coronary artery disease, stroke, peripheral vascular disease (PVD) and smoking had a statistical tendency $(p<0.20)$ and, therefore, were included in the logistic regression model (Table 1 ).

Multivariable logistic regression detected the following independent risk factors for hospital readmission: left

Table 1 - Univariable predictors of rehospitalization within 30 days after discharge

\begin{tabular}{|c|c|c|c|c|c|}
\hline Variable & $\begin{array}{l}\text { Overall cohort } \\
\quad(n=312)\end{array}$ & $\begin{array}{l}\text { No readmission } \\
\quad(n=241)\end{array}$ & $\begin{array}{l}\text { Readmission } \\
\quad(n=71)\end{array}$ & $\begin{array}{l}\text { OR univariate } \\
95 \% \mathrm{CI}\end{array}$ & p-value \\
\hline Age $\geq 65$ years & $232(74.4 \%)$ & $176(73.0 \%)$ & $56(78.9 \%)$ & $1.38(0.73-2.61)$ & 0.322 \\
\hline Male gender & $194(62.2 \%)$ & $151(62.7 \%)$ & $43(60.6 \%)$ & $0.92(0.53-1.58)$ & 0.749 \\
\hline \multicolumn{6}{|l|}{ Etiology } \\
\hline Ischemic & $179(57.6 \%)$ & $133(55.4 \%)$ & $46(64.8 \%)$ & 1.0 & - \\
\hline Hypertensive & $54(17.4 \%)$ & $45(18.8 \%)$ & $9(12.7 \%)$ & $0.58(0.26-1.27)$ & 0.274 \\
\hline Idiopathic & $32(10.3 \%)$ & $25(10.4 \%)$ & $7(9.9 \%)$ & $0.81(0.33-1.99)$ & 0.646 \\
\hline Valvar & $19(6.1 \%)$ & $16(6.7 \%)$ & $3(4.2 \%)$ & $0.54(0.15-1.95)$ & 0.348 \\
\hline Others & $27(8.7 \%)$ & $21(8.8 \%)$ & $6(8.5 \%)$ & $0.83(0.31-2.17)$ & 0.699 \\
\hline NYHA - Class IV & $154(49.5 \%)$ & $119(49.6 \%)$ & $35(49.3 \%)$ & $0.99(0.58-1.68)$ & 0.966 \\
\hline ACS cause of decompensation & $140(45.9 \%)$ & $100(42.6 \%)$ & $40(57.1 \%)$ & $1.80(1.12-3.16)$ & $0.032^{*}$ \\
\hline Hypertension & $268(85.9 \%)$ & $203(84.2 \%)$ & $65(91.5 \%)$ & $2.03(0.82-5.01)$ & 0.120 \\
\hline Diabetes mellitus & $153(49.0 \%)$ & $115(47.7 \%)$ & $38(53.5 \%)$ & $1.26(0.74-2.14)$ & 0.390 \\
\hline Coronary disease & $202(64.7 \%)$ & $150(62.2 \%)$ & $52(73.2 \%)$ & $1.66(0.92-2.99)$ & 0.088 \\
\hline Kidney disease & $94(30.1 \%)$ & $69(28.6 \%)$ & $25(35.2 \%)$ & $1.32(0.77-2.38)$ & 0.288 \\
\hline Valvar disease & $22(7.1 \%)$ & $19(7.9 \%)$ & $3(4.2 \%)$ & $0.55(0.15-1.79)$ & 0.290 \\
\hline COPD/asthma & $57(18.3 \%)$ & $47(19.5 \%)$ & $10(14.1 \%)$ & $0.68(0.32-1.42)$ & 0.299 \\
\hline Neoplasia & $28(9.0 \%)$ & $22(9.1 \%)$ & $6(8.5 \%)$ & $0.92(0.36-2.37)$ & 0.861 \\
\hline Stroke & $31(9.9 \%)$ & $21(8.7 \%)$ & $10(14.1 \%)$ & $1.72(0.77-3.84)$ & 0.184 \\
\hline Peripheral vascular disease & $60(19.2 \%)$ & $42(17.4 \%)$ & $18(25.4 \%)$ & $1.61(0.56-3.02)$ & 0.136 \\
\hline Alcohol use & $69(22.1 \%)$ & $57(23.7 \%)$ & $12(16.9 \%)$ & $0.66(0.33-1.31)$ & 0.231 \\
\hline Smoking & $76(24.4 \%)$ & $63(26.1 \%)$ & $13(18.3 \%)$ & $0.63(0.23-1.23)$ & 0.277 \\
\hline $\begin{array}{l}\text { Systolic BP on admission } \\
<115 \mathrm{mmHg}\end{array}$ & $73(23.4 \%)$ & $58(24.1 \%)$ & $15(21.1 \%)$ & $0.85(0.45-1.61)$ & 0.607 \\
\hline $\begin{array}{l}\text { Heart rate on admission } \\
\leq 80 \mathrm{bpm}\end{array}$ & $139(44.6 \%)$ & $106(44.0 \%)$ & $33(46.5 \%)$ & $1.11(0.65-1.88)$ & 0.710 \\
\hline
\end{tabular}


Cont. Table 1 - Univariable predictors of rehospitalization within 30 days after discharge

\begin{tabular}{|c|c|c|c|c|c|}
\hline Variable & $\begin{array}{l}\text { Overall cohort } \\
\qquad(\mathrm{n}=312)\end{array}$ & $\begin{array}{l}\text { No readmission } \\
\qquad(\mathrm{n}=241)\end{array}$ & $\begin{array}{c}\text { Readmission } \\
\quad(\mathrm{n}=71)\end{array}$ & $\begin{array}{c}\text { OR univariate } \\
95 \% \mathrm{CI}\end{array}$ & p-value \\
\hline Betablockers in hospital & $237(76.9 \%)$ & $179(75.5 \%)$ & $58(81.7 \%)$ & $1.45(0.74-2.83)$ & 0.279 \\
\hline ACEI/ARB in hospital & $239(77.3 \%)$ & $187(78.6 \%)$ & $52(73.2 \%)$ & $0.75(0.41-1.37)$ & 0.342 \\
\hline LVEF $<40 \%(+)$ & $126(43.0 \%)$ & $85(38.3 \%)$ & $41(57.7 \%)$ & $2.20(1.28-3.79)$ & $0.004^{*}$ \\
\hline Hyponatremia on admission & $24(7.7 \%)$ & $14(5.8 \%)$ & $10(14.1 \%)$ & $2.65(1.12-6.25)$ & $0.022^{*}$ \\
\hline $\begin{array}{l}\text { Abnormal blood urea nitrogen } \\
\text { on admission }\end{array}$ & $47(15.2 \%)$ & $36(15.1 \%)$ & $11(15.5 \%)$ & $1.03(0.49-2.14)$ & 0.940 \\
\hline $\begin{array}{l}\text { Abnormal creatinine on } \\
\text { admission }\end{array}$ & $126(40.5 \%)$ & $97(40.4 \%)$ & $29(40.8 \%)$ & $1.29(0.76-2.22)$ & 0.948 \\
\hline Anemia on admission & $163(52.8 \%)$ & $122(51.3 \%)$ & $41(57.7 \%)$ & $1.02(0.59-1.75)$ & 0.337 \\
\hline $\begin{array}{l}\text { Complication during } \\
\text { hospitalization }\end{array}$ & $81(25.9 \%)$ & $61(25.3 \%)$ & $20(28.2 \%)$ & $1.18(0.65-2.14)$ & 0.597 \\
\hline Hospitalization period $>7$ days & $198(63.5 \%)$ & $150(62.2 \%)$ & $48(67.6 \%)$ & $1.27(0.72-2.21)$ & 0.409 \\
\hline
\end{tabular}

ventricular ejection fraction $<40 \%(\mathrm{OR}=2.11 ; 95 \% \mathrm{CI}$ $1.21-3.69)$, hyponatremia on admission (OR $=2.87 ; 95 \%$ CI 1.16-7.07) and ACS as a cause of decompensation (OR $=1.89 ; 95 \%$ CI $1.08-3.31)$. The final model with these three variables presented a reasonable discrimination capability (C-statistic $=0.655-95 \%$ CI: $0.582-0.728)$ and good calibration (Hosmer-Lemeshow: $\chi 2=0.892, \mathrm{p}=$ 0.925). Figure 2 shows the graphic representation of those variables and their respective odds ratio and 95\% CI.

\section{Discussion}

This study contributed to the comprehension of the dynamics of hospital readmission of patients with HF, which has become more prevalent among the population, due to increase of population and life expectancy. Therefore, the concern with the improvement of clinical conditions and survival rate is justified, contributing to better planning of health actions.

The main characteristic of the studied population is the profile of high severity and complexity and advanced age: more than $70 \%$ were elderly (over 65) with many comorbidities. This configuration can be explained by the fact that the studied hospital is a reference in cardiology in the North and Northeast of Brazil. The profile is similar to the population on international records, such as ADHERE done in multiple health centers in the USA with more than 118,000 patients between 2001 and 2004, whose average age was 73 and $50 \%$ were men. ${ }^{9}$ On the other hand, the 1st Brazilian Registry of Heart Failure BREATHE - done in 51 hospitals (public and private) from different parts of Brazil, reported younger age on average ( $64 \pm 16$ years), majority of women and infection as the main causes of decompensation. ${ }^{4}$

Considering the etiology of $\mathrm{HF}$, the most frequent one found in our population was ischemic etiology (58\%), followed by hypertensive (17\%), corroborating most of the studies. ${ }^{10-12}$ When we looked at the northeastern states only, in the BREATHE registry, the percentage of hypertensive and valvar etiology were greater than the ones observed in that population. ${ }^{4}$

The average time of hospitalization for compensation, among our patients, was 13 days, which superior to that in the literature, with an average time of 9 days for the most critical cases. ${ }^{12}$ Despite the technological progress achieved in the last decades, such as new drugs, pacemaker and resynchronizer use, the length of stay and in-hospital mortality of the patients with HF is increasing in Brazil, and, automatically, the average cost of hospitalization has increased significantly from 


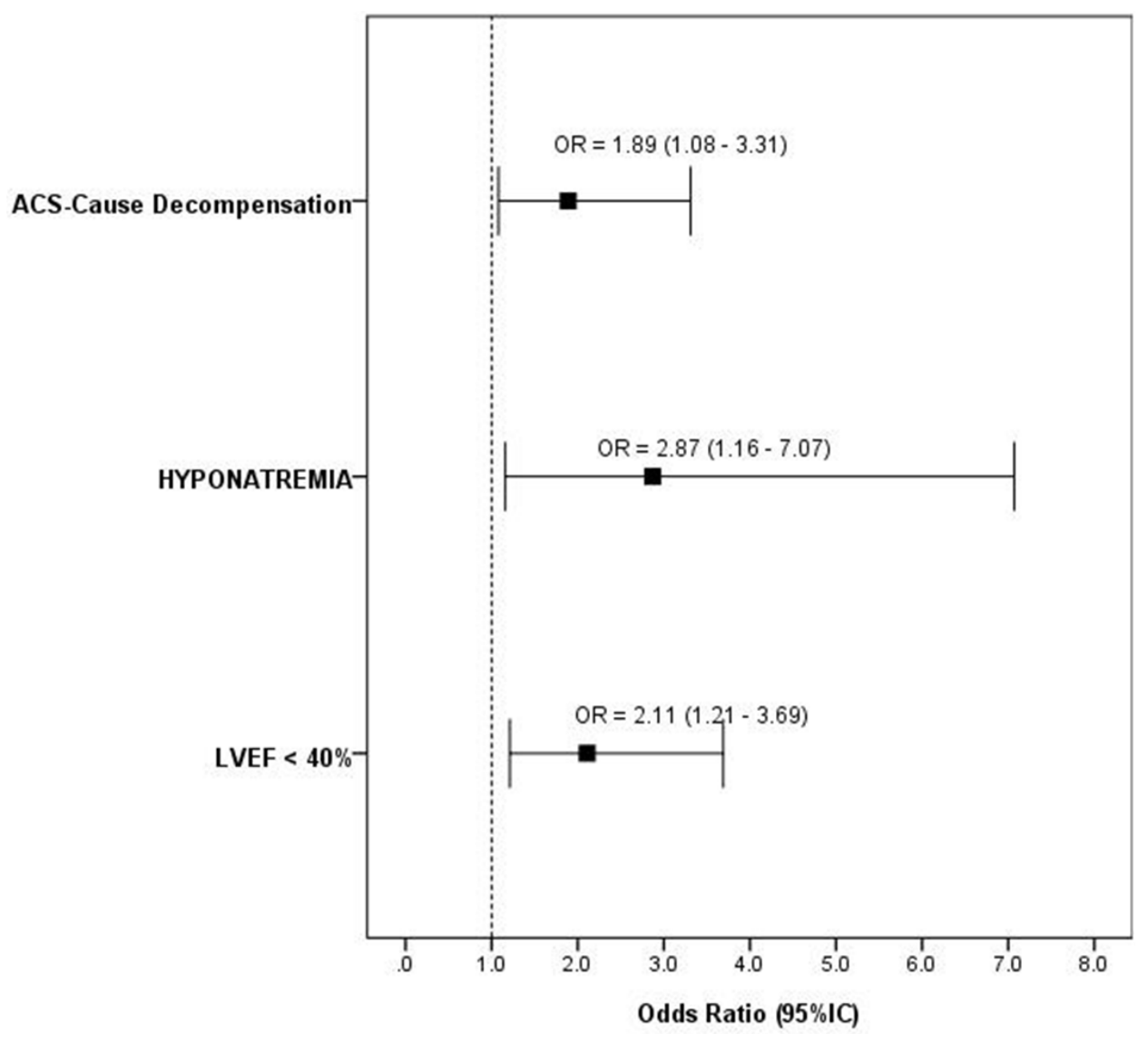

Figure 2 - Multivariable model for 30-Days readmission - Odds Ratio (95\%CI).

ACS: acute coronary syndrome; LVEF: left ventricular ejection fraction.

BRL 920 in 2008 to BRL 1,559 in 2016. ${ }^{13-14}$ A possible explanation to the increased length of stay may be due to the fact that the study was conducted at a private hospital, where there is no major issues of scarcity of hospital beds, hence less pressure from the public health system for early patient discharge.

In this study, the readmission rate of patients with DHF within 30 days of discharge was $23 \%$, which is consistent with other published studies, in which $24 \%$ of the participants were readmitted within 30 days. ${ }^{15-17}$

Historically, several measurements have been proposed in order to create models of HF prognostic prediction; however, those models have presented limited predictive capabilities, as we are dealing with a chronic disease whose outcome is associated with multiple causes, including the form of presentation and severity of the disease, clinical and behavioral characteristics of the patients, in addition to factors such as failure of the health system, which is not comparable to models from developed countries. In a systematic review of 30 studies that developed models of hospital readmission prediction, the C-statistic varied from 0.55 to 0.65 , demonstrating the inexistence of predictor scores of high discriminatory power. ${ }^{18}$

Among 26 analyzed variables of hospital readmission within 30 days of discharge, using the multivariable logistic model, this study identified the following factors as predictors of independent risk: LVEF $<40 \%$, hyponatremia and ACS as causes of decompensation. The final logistic model presented a reasonable discriminatory power (C-statistic $=0.655-95 \%$ CI $0.582-0.728)$ and good calibration (Hosmer-Lemeshow: $\chi^{2}=0.892, \mathrm{p}=0.925$ ).

It was demonstrated that patients with hyponatremia at the time of hospital admission had three times more chance of readmission (95\% CI 1.01 - 11.19) in comparison with those with normal sodium levels. Notwithstanding 
the wide reliability interval, this estimate could be considered as relatively early, however, this estimate is consistently present in other studies of this literature as well. A study developed in Boston in 2014 demonstrated that patients with low sodium levels presented an odds ratio of 1.45 on readmission within 30 days..$^{15}$ In a meta-analysis of observational studies, developed by Saito in 2015, including 57 articles, the importance of hyponatremia as a marker of bad prognosis of HF was also attested..$^{19}$

Corroborating previous studies, reduced left ventricle ejection fraction (LVEF) was an independent risk predictor of readmissions. ${ }^{19-20}$ In the American study, it was demonstrated that LVEF $<45 \%$ had a direct association with hospital readmission due to other causes, with a risk of $1.25 .^{21}$

Data suggested that acute coronary syndrome (ACS) as a cause of decompensation is a relevant risk factor associated with readmission within 30 days of discharge. Unlike other precipitating factors of HF decompensation, such as excessive salt intake infections, lack of commitment to the treatment, among others, ACS cannot be prevented. Heart attack survivors have consistent risk of developing HF. Lower risk of HF can be related to decrease of comorbidities and/or evidencebased treatment. The possibility that the new heart injury secondary to the new acute coronary finding impacts an outcome of early hospital readmission is suggested here. ${ }^{22}$ From this standpoint, patients with that condition can only be identified and from that, a more intensive strategy can be created at the post-discharge service.

In this study, $49 \%$ of patients declared having diabetes as a comorbidity. Of these, $25 \%$ returned within 30 days of discharge, whereas, among non-diabetics, this percentage was $21 \%$, not showing evidence that that factor is a possible risk factor of early readmission. Nevertheless, an analysis of more than 600 individuals identified type II DM as an independent predictor of readmission, as in Huynh's study of 2015, in which DM was classified as a moderate criterion in models of shortterm prediction. . $^{1923-24}$

The variables of gender and age were not predictors of hospital readmission. Regarding social factors, there is great controversy if those are or not predictors of HF prognosis. Some studies demonstrated the correlation of those variables with clinical outcomes, such as death and readmissions. ${ }^{15}$ Paradoxically, a study conducted at a hospital in Tasmania tested two models of rehospitalization prediction: one including clinical data and another with non-clinical data such as gender, age, whether the person lives alone, and so on. The author demonstrated that the model with clinical data reported a better discriminatory power for hospital readmission..$^{25}$

High levels of creatinine and urea are associated with worse in-hospital survival and outcome after discharge. ${ }^{15,26}$ The risk score ADHERE - a globally accepted score for the prediction of in-hospital mortality due to HF - takes in consideration only those two markers, in addition to systolic blood pressure. ${ }^{9}$ Nevertheless, in this study, although creatinine and urea levels are biologically plausible, they did not present any relevant association with readmissions, possibly due to no statistical power detected in such correlations. As in the HF spectrum, in systolic blood pressure on admission, there was no confirmed association with readmission.

In this study, betablockers (BB), as well as the association of angiotensin-converting enzyme inhibitors (ACEI) and angiotensin receptor blockers (ARB), were prescribed during hospitalization to the majority of the patients $(77 \%)$, a much higher number than the ones announced by the BREATHE registry, which were $57 \%$ of BB, $42 \%$ of ACEI and $24 \%$ of ARB. Considering HF patients, with reduced LVEF, the indication was higher: $82 \%$ in the case of ACEI/ARB and $84 \%$ for betablockers. These findings highlight the practice of the studied center in following the recommended standards, in line with the guidelines from several countries, as well as the Brazilian Guideline for Chronic HF, in which there is a consensus on the therapeutic use of $\mathrm{BB}$ drugs related to ACEI and ARB, their well-established clinical benefits on death caused by HF, besides the improvement of symptoms and reduction of readmission due to HF., ${ }^{47-}$ ${ }^{29}$ Nevertheless, in our specific population, the use of those medications during hospitalization was not confirmed as a protection factor against readmissions in the short-run. This might be explained by the fact that commitment and continuous use of therapeutic are largely associated with patient evolution than with its prescription during hospitalization.

The biochemical marker troponin as well as B-type natriuretic peptide (NT-proBNP) were validated in previous studies as relevant predictors of readmissions, however in this study, they were not analyzed due to the limited number of patients with those information from exams, as in our Brazilian reality, both troponin and NTproBNP are not requested from all patients. ${ }^{30}$ 
Economic and social aspects were not considered in this study, since it was based on a historical cohort, with medical record data. The operation of these variables, from the quantitative point of view, was limited both by the inexistence of information and by the quality and reliability of the information present on the medical records.

Ziaian concluded, in his article, that the risk of hospital readmission is also related to the behavior of healthcare professionals, such as strategies that lead to greater support to discharging patients, better communication and earlier outpatient care. ${ }^{29}$ Another factor that has an influence on hospital readmission rates is the hospital structure. In the Bergethon study, university hospitals presented higher relative readmission rate in comparison with their peers, and the hospitals that used disease management programs had lower relative readmission rates. ${ }^{31}$

It is very important to validate the reproduction of literature findings in our own population, as we are dealing with patients from the private health system and it is well known that their socio-economic and clinical profile differ from those of the patients seen by the public health system, besides the access to healthcare, which is very distinct between the two groups of patients. According to official data from the National Health Agency of Brazil, in 2003, the private health system received around 35 million beneficiaries. In 2016, this number raised to 48 million, an increase of $37 \%$ in 13 years. ${ }^{32}$ The private health system has been crucial to the State, as it supports the National Health System itself, helping to meet the national demand for healthcare.

The data must be interpreted from the light of its limitations. The study was based on only one hospital facility, even though that facility is a reference in cardiology treatments in the North and Northeast of Brazil, where there is still some lack of information. The size of the sample group was limited, and the data was taken from medical records, implying that all relevant data were registered precisely, however, unknown prognostic factors or the ones not registered may have influenced the results.

As stated previously, it is possible to recognize that, according to several discussed studies, there is no single model of risk prediction of hospital readmission from HF. The epidemiological and clinical characteristics of each population require local validation of those risk tools as a way to find out the relevant predictors to complement clinical practice in determining the best care to be given to patients with that syndrome. From this perspective, in the context of a healthcare system with a multidisciplinary profile capable of offering full patient assistance, taking in consideration all biological, psychological and social determinants, it is important to have a follow-up plan to support patients and families.

In a sample of patients admitted at the private health system with DHF, the readmission rate was over $20 \%$, and factors such as reduced left ventricular ejection fraction, hyponatremia and ACS as causes of decompensation were strong markers of hospital readmission within 30 days of discharge. Acknowledgement and evaluation of these findings are helpful for policymaking in the public healthcare system, with actions aiming at treatment and care for those patients. The healthcare and scientific communities must practice critical epidemiology based on a wider comprehension of reality, seeking better evidence in order to protect life and not only health.

\section{Author contributions}

Conception and design of the research: Sarteschi C, Cesse EAP, Martins SM. Acquisition of data: Sarteschi C, Medeiros C. Analysis and interpretation of the data: Sarteschi C, Martins SM. Statistical analysis: Sarteschi C. Obtaining financing: Sarteschi C. Writing of the manuscript: Sarteschi C. Critical revision of the manuscript for intellectual content: Sarteschi C, Cesse EAP, Martins SM, Souza WV. Supervision / as the major investigador: Sarteschi C.

\section{Potential Conflicts of Interest}

There are no relevant conflicts of interest to be declared.

\section{Funding Sources}

The present study was funded by Capes.

\section{Academic Association}

The present study is part of a PhD thesis by Sarteschi C., presented to Programa de Pos-Graduação em Saúde Pública do Centro de Pesquisas Aggeu Magalhães Fiocruz/PE. 


\section{Ethics approval and consent to participate}

This study was approved by the Ethics Committee of the Universidade Católica de Pernambuco under the protocol number 70891517.8.000.5206. All the procedures in this study were in accordance with the 1975 Helsinki Declaration, updated in 2013. Informed consent was obtained from all participants included in the study.

\section{References}

1. Schmidt MI, Duncan BB, Azevedo e Silva G, Menezes AM, Monteiro CA Barreto SM, et al. Chronic non-communicable diseases in Brazil: burden and current challenges. Lancet. 2011;377(9781):1949-61.

2. Cleland JG, Khand A, Clark A. The heart failure epidemic: exactly how big is it? Eur Heart J. 2001;22(8):623-6.

3. Ministério da Saúde [internet].Departamento de Informática do SUS Sistema de Informaç̃es Hospitalares do SUS. Brasília; 2004. [acesso em 16 maio 2017]. Disponível em: http://www.datasus.gov.br.html.

4. Albuquerque DC, Souza Neto JD, Bacal F, Rodhe LEP, Pereira SB, Berwanger $\mathrm{O}$, et al. I Brazilian Registry of Heart Failure - Clinical Aspects, Care Quality and Hospitalization Outcomes. Arq Bras Cardiol. 2015;104(6):433-42.

5. Cowie MR, Fox KF, Wood DA, Metcalfe C, Thompson SG, Coasts AJ, et al. Hospitalization of patients with heart failure: a population-based study. Eur Heart J. 2002;23(11):877-85.

6. Felker GM, Benza RL, Chandler AB, Leimberger JD, Cuffe MS, Califf RM, et al. Heart failure etiology and response to milrinone in decompensated heart failure: results from the OPTIME-CHF study. J Am Coll Cardiol. 2003;41(6):997-1003.

7. Ho KK, Pinsky JL, Kannel WB, Levy D. The epidemiology of heart failure: the Framingham study. J Am Coll Cardiol. 1993;22(4 Suppl A):6A-13A.

8. Lang RM, Badano LP, Mor-Avi V, Afilalo J, Armstrong A, Ernande $\mathrm{L}$, et al. Recommendations for cardiac chamber quantification by echocardiography in adult: an update from the American Society of Echocardiography and the European Association of Cardiovascular Imaging. Eur Heart J Cardiovasc Imaging. 2015;16(3):233-70.

9. Fonarow GC, Heywood JT, Heidenreich PA, Lopatin M, Yancy CW, ADHERE Scientific Advisory Committee and Investigators. Temporal trends in clinical characteristics, treatments, and outcomes for heart failure hospitalizations, 2002 to 2004: findings from acute decompensated Heart Failure National Registry (ADHERE). Am Heart J. 2007;153(6):1021-8

10. Abraham WT, Fonarow GC, Albert NM, Stough WG, Gheorghiade $\mathrm{M}$, Greenberg BH, et al. Investigators and Coordinators. Predictors of in-hospital mortality in patients hospitalized for heart failure: insights from the Organized Program to Initiate Lifesaving Treatment in Hospitalized Patients with Heart Failure (OPTIMIZE-HF). J Am Coll Cardiol. 2008;52(5):347-56.

11. Pocock SJ, Wang D, Pfeffer MA, Yusuf S, McMurray JJ, Swedberg KB, et al. Predictors of mortality and morbidity in patients with chronic heart failure. Eur Heart J. 2006;27(1):65-75.

12. Rohde LE, Clausell N, Ribeiro JP, Goldraich L, Netto R, William Dec G, et al. Heath outcomes in decompensated congestive heart failure: comparison of tertiary hospitals in Brazil and United States. Int J Cardiol. 2005;102(1):71-7

13. BRASIL. Ministério da Saúde [internet]. Departamento de Informática do SUS. Sistema de Informações Hospitalares do SUS. Brasília; 2004. [acesso em 05 junho 2017]. Disponível em: http:www.datasus.gov.br.html.

14. Kaufman R, Azevedo VMP, Xavier RMA, Geller M, Chaves RBM, Castier MB. Evolution of Heart Failure-related Hospital Admissions and Mortality Rates: a 12-Year Analysis. Int J Cardiovasc Sci. 2015;28(4):276-81.
15. Fleming LM, Gavin M, Piatkowski G, Chang JD, Mukamal KJ. Derivation and validation of a 30-day heart failure readmission model. Am J Cardiol. 2014;114(9):1379-82.

16. Bottle A, Goudie R, Cowie MR, Bell D, Aylin P. Relation between process measures and diagnosis-specific readmission rates in patients with heart failure. Heart. 2015;101(21):1704-10.

17. Krumholz HM, Chen YT, Vaccarino V, Wang Y, Radford MJ, Bradford $\mathrm{WD}$, et al. Correlates and impact on outcomes of worsening renal function in patients $\geq 65$ years of age with heart failure. Am J Cardiol. 2000;85(9):1110-3.

18. Kansagara D, Englander H, Salanitro A, Kagen D, Theobald C, Freeman $\mathrm{M}$, et al. Risk prediction models for hospital readmission: a systematic review. JAMA. 2011;306(15):1688-98.

19. Saito M, Negishi K, Marwick TH. Meta-analysis of risks for short-term readmission in patients with heart failure. Am J Cardiol.2016;117(4):626-32.

20. Rahimi K, Bennett D, Conrad N, Williams TM, Basu J, Dwight J, et al. Risk prediction in patients with heart failure. JACC Heart Fail. 2014;2(5):440-6

21. Chaudhry SI, McAvay G, Chen S, Whitson H, Newman AB, Krumholz $\mathrm{HM}$, et al. Risk factors for hospital admission among older persons with newly diagnosed heart failure: findings from the cardiovascular health study. J Am Coll Cardiol. 2013;61(6):635-42.

22. Desta L, Jernberg T, Spaak J, Hofman-Bang C, Persson H. Risk and predictors of readmission for heart failure following a myocardial infarction between 2004 and 2013: a Swedish nationwide observational study. Int J Cardiol. 2017 Dec 1;248:221-6.

23. Cubbon RM, Woolston A, Adams B, Gale CP, Gilthorpe MS, Baxter PD et al. Prospective development and validation of a model to predict heart failure hospitalisation. Heart. 2014;100(12):923-9.

24. Cavender MA, Steg PG, Smith SC Jr, Eagle K, Ohman EM, Goto S, et al. Impact of diabetes mellitus on hospitalization for heart failure, cardiovascular events, and death. outcomes at 4 years from the Reduction of Atherothrombosis for Continued Health (REACH) Registry. Circulation. 2015;132(10):923-31

25. Huynh QL, Saito M, Blizzard CL, Eskandari M, Johnson B, Adabi G, et al. Roles of nonclinical and clinical data in prediction of 30-day rehospitalization or death among heart failure patients. J Card Fail. 2015;21(5):374-81.

26. Millane T, Jackson G, Gibbs CR, Lip GY. ABC of Heart Failure. Acute and chronic management strategies. BMJ. 2000;320(7234):559-62.

27. Bocchi EA, Marcondes-Braga FG, Bacal F, Ferraz AS, Albuquerque D Rodrigues D, et al. Atualização da Diretriz brasileira de insuficiência cardíaca crônica - 2012. Arq Bras Cardiol. 2012;98(1 supl. 1):1-33.

28. Montera MW, Almeida DR, Tinoco EM, Rocha RM, Moura LAZ, RéaNeto A, et al. II Diretriz Brasileira de Insuficiência Cardíaca Aguda. Arq Bras Cardiol. 2009;93(3 supl.3):1-65.

29. Ziaeian B, Fonarow GC. The prevention of hospital readmissions in heart failure. Prog Cardiovasc Dis. 2016;58(4):379-85.

30. Xin W, Lin Z, Mi S Does B-type natriuretic peptide-guided therapy improve outcomes in patients with chronic heart failure? A systematic review and meta-analysis of randomized controlled trials. Heart Fail Rev. 2015;20(1):69-80. 
31. Bergethon KE, Ju C, DeVore AD, Hardy NC, Fonarow GC, Yancy CW, et al. Trends in 30-day readmission rates for patients hospitalized with heart failure: findings from the get with the guidelines-heart failure registry. Circ Heart Fail. 2016;9(6): e002594.
32. Brasil. Ministério da Saúde [internet]. Agencia Nacional suplementar de Saude. Informação em Saúde Suplementar. [acesso em 15 marco 2017]. Disponível em: http:www.ans.gov.br/perfil-do-setor/dados-eindicadores-do-setor. 